\title{
DA SOBREASSEVERAÇÃO PARA A AFORIZAÇÃO: PERCURSO TEÓRICO PARA UM REGIME ENUNCIATIVO
}

\author{
FROM SURASSERTION TO \\ APHORIZATION: A THEORETICAL PATH \\ DE LA SOBREASSEVERACIÓN PARA \\ TOWARDS A REGIME OF ENUNCIATION \\ AFORIZACIÓN: RECORRIDO TEÓRICO \\ PARA UN RÉGIMEN DE ENUNCIACIÓN
}

\author{
Luís Rodolfo Cabral*
}

Instituto Federal do Maranhão, Santa Inês, MA, Brasil

\begin{abstract}
Resumo: O objetivo deste trabalho é traçar um percurso teórico para o regime aforizante, desenvolvido detalhadamente na obra de Dominique Maingueneau Frases sem texto (Les phrases sans texte, Paris, 2012), lançada no Brasil em 2014. A teoria sobre a aforização é resultado de, pelo menos, dez anos de pesquisa, e com o levantamento bibliográfico das publicações sobre o assunto a partir de 2004, o estudo explicita a progressiva construção do estatuto pragmático desse regime enunciativo, mais especificamente no que concerne às noções de sobreasseveração e aforizador. Levanta uma breve discussão sobre responsabilidade enunciativa de forma a evidenciar como se constrói a noção de sujeito da enunciação nesse regime. Este trabalho busca dirimir a diversidade terminológica em torno dos conceitos que essa teoria mobiliza, e apresentar uma revisão teórica para os iniciantes no assunto.
\end{abstract}

Palavras-chave: Frases sem texto. Aforização. Regime aforizante.

\begin{abstract}
This paper aims to outline a theoretical path for a specific regime of enunciation named aphorization, which is developed in detail on Dominique Maingueneau's work entitled Frases sem texto (Les phrases sans texte, Paris, 2012), launched in Brazil in 2014. The theory of aphorization is a result of at least ten years of research, and with a bibliographic survey of publications about the subject from 2004 onwards, this paper makes explicit the progressive construction of the pragmatic statute for this regime of enunciation, specifically regarding to the notions of surassertion and aphorizer (the enunciator of an aphorization). It briefly discusses about enunciative responsibility in order to emphasize the development process of the subject of enunciation in this regime, as well as intends to clarify the terminological diversity concerning the concepts mobilized by this theory. At last, the research presents a theoretical review for beginners.
\end{abstract}

Keywords: Texteless sentences. Aphorization. Aphorizing regime.

Resumen: El objetivo de ese trabajo es trazar un recorrido teórico para el régimen aforizante, desarrollado detalladamente en la obra Frases sin texto (Frases sem texto), de Dominique Maingueneau, lanzada en Brasil el año de 2014. La teoría sobre aforización es resultado de por lo menos diez años de investigación, y con encuesta bibliográfica de publicaciones sobre el tema desde 2004, el estudio haz explicita la progresiva construcción del estatuto pragmático de ese régimen enunciativo, más específicamente con respeto a nociones de sobreasseveración y aforizador. Trae una breve discusión sobre responsabilidad enunciativa de manera a hacer evidente cómo se construye la noción de sujeto da enunciación en ese régimen. Ese trabajo busca resolver la diversidad terminológica sobre los conceptos que esa teoría moviliza, y presentar una revisión teórica para los iniciantes en el asunto.

Palabras clave: Frases sem texto. Aforización. Régimen aforizante.

* Professor do Instituto Federal do Maranhão - Campus Santa Inês. ORCID: https://orcid.org/0000-00015456-8927 Email: rodolfo.cabral@ifma.edu.br. 
No livro Les phrases sans texte, publicado na França em 2012 e traduzido no Brasil em 2014 com o título Frases sem texto, Maingueneau desenvolve uma teoria sobre um regime enunciativo a partir da observação de que há frases que funcionam de maneira autônoma: algumas circulam da forma como foram produzidas originalmente - como os provérbios, por exemplo; e outras são postas a circular independentemente do texto de origem e do contexto em que foram produzidas. Esses dois tipos de frases são chamados aforizações, ou seja, são enunciados produzidos pelo regime enunciativo aforizante.

Grosso modo, a aforização (termo usado para se referir tanto ao processo quanto ao produto) é uma enunciação relacionada à produção de enunciados autossuficientes que estão situados em um texto e, paradoxalmente, aspiram a sair dele. Nessa perspectiva, Maingueneau entende que as aforizações atribuem um novo estatuto à citação, pois não se trata de uma retomada, mas de uma forma de apresentação, de tornar enigmático um enunciado que manifesta e esconde tudo ao mesmo tempo, e que apela para a interpretação.

$\mathrm{Na}$ tentativa de contribuir com a divulgação dos estudos sobre esse regime enunciativo, este texto realiza um levantamento bibliográfico dos trabalhos de Maingueneau sobre aforização, publicados antes da obra de 2012, de modo a traçar um percurso cronológico do desenvolvimento dessa teoria e a evidenciar os avanços de pesquisa sobre o regime aforizante ao longo dos anos. Além disso, também é objetivo deste trabalho dirimir a diversidade terminológica em torno dos conceitos que essa teoria mobiliza, e apresentar uma revisão teórica para os iniciantes no assunto.

Este texto está organizado em três partes, fora esta introdução e as considerações finais,: na primeira são apresentados os textos selecionados para a discussão teórica e o critério de escolha; na segunda, discorre-se sobre as motivações iniciais de Maingueneau para construir a noção de sobreasseveração; na terceira, são estabelecidas as distinções necessárias para as definições de um estatuto pragmático do regime aforizante no que se refere ao aforizador e ao auditório.

\section{LEVANTAMENTO BIBLIOGRÁFICO}

Neste trabalho, são discutidos sete textos de Maingueneau, publicados entre os anos de 2004 e 2012 na forma de artigos ou de capítulos de livros, dispostos no quadro 1. Para chegar a este quantitativo, parte-se das referências a trabalhos anteriores utilizadas em Les phrases sans texte, e descartando-se aqueles que abordam questões como enunciação proverbial, particitação, panaforização, enquadramento e supradestinatário. Tais questões são consideradas desdobramentos do estatuto pragmático deste regime enunciativo. 


\begin{tabular}{|l|l|l|l|}
\hline Texto original & Ano & Tradução ao português brasileiro & Ano \\
\hline Citation et surassertion & 2004 & Citação e destacabilidade $^{1}$ & 2008 \\
\hline $\begin{array}{l}\text { Les énoncés détachés dans la presse écrite: de la } \\
\text { surassertion á l'aphorisation }\end{array}$ & 2006 & - & - \\
\hline Les énoncés détachés & 2007 & Enunciados destacados ${ }^{2}$ & 2013 \\
\hline L' énonciation aphorisante & 2007 & - & - \\
\hline $\begin{array}{l}\text { Aforização: enunciados sem texto? (original em } \\
\text { português brasileiro) }\end{array}$ & 2010 & & 2010 \\
\hline $\begin{array}{l}\text { Enunciação ligada, enunciação desatada } \\
\text { (original em português brasileiro) }\end{array}$ & 2012 & & 2012 \\
\hline $\begin{array}{l}\text { Texto, gênero do discurso e aforização } \\
\text { (original em português brasileiro) }\end{array}$ & 2012 & & 2012 \\
\hline
\end{tabular}

\section{Quadro 1 - Levantamento bibliográfico sobre regime aforizante em Maingueneau (2004- 2012)}

Fonte: Elaborado pelo autor (2019).

Tendo em vista que o objetivo deste trabalho é traçar um percurso cronológico, será feita referência à primeira data de publicação, ainda que se recorra à tradução brasileira, quando houver. Caso não haja, será apresentada nossa tradução, com o trecho original em nota de rodapé.

\section{A SOBREASSEVERAÇÃO}

O primeiro texto de Maingueneau a tratar do assunto é o intitulado Citation et surassertion, publicado na revista Polifonia em dezembro de 2004, em que problematiza aspectos da citação para os casos em que há indícios flagrantes de que um dado enunciado foi construído visando a um destacamento e circulação ulterior. Essa discussão se estende em outros dois textos posteriores: no artigo Les énoncés détachés dans la presse écrite, publicado na revista Revue Tranel, em 2006; e no texto L'énonciation aphorisante, incluído nos anais do V Congresso Nacional da Associação Brasileira de Linguística, em 2007. Como muitas das reflexões desenvolvidas nesses três textos são retomadas em todas as produções subsequentes, avaliamos que eles constituem o núcleo teórico para o desenvolvimento da teoria sobre as aforizações.

Com o objetivo de discutir esse funcionamento autônomo das fórmulas ${ }^{3}$, Maingueneau examina as "citações célebres", mais especificamente as máximas heroicas e as fórmulas filosóficas. As sequências autônomas deste primeiro grupo são comuns no teatro clássico francês do século XVII, em cujas produções há recorrência de asserções generalizantes, curtas, facilmente memoráveis e reutilizáveis, ainda que a não originalidade do conteúdo seja questionável.

\footnotetext{
${ }^{1}$ A versão traduzida por Roberto Leiser Baronas está incluída no livro Cenas da enunciação, de onde foram extraídos os trechos em português.

${ }^{2}$ Refere-se ao capítulo 18 de Análise de textos de comunicação, incluído na edição ampliada do livro.

${ }^{3}$ A priori, dada a propriedade de cristalização, os enunciados destacados do campo filosófico são tratados como fórmulas. Essa abordagem vai perdendo força à medida que a teoria se desenvolve, como se pode ver nos registros de Frases sem texto. Para uma revisão teórica sobre fórmula discursiva, ver KriegPlanque (2010).
} 
Aprofundando essa investigação, as propriedades de destacabilidade das máximas heroicas são examinadas a partir de duas falas de Rodrigo, personagem de Cid, obra de Corneille ${ }^{4}$. Do ponto de vista enunciativo, Maingueneau (2004) chama a atenção para os verbos dessas sequências, os quais, apesar de conjugados no tempo presente, não se opõem nem ao passado nem ao futuro, funcionando como asserção de uma verdade atemporal para qualquer situação. Pela combinação paradoxal de ineditismo e imemorialidade, produz-se a expectativa de destacabilidade nessas fórmulas: o enunciado é digno de ser consagrado porque se apresenta como novo e, ao mesmo tempo, aspira a um estatuto de perenidade ao inaugurar a possibilidade de uma série de retomadas.

Para examinar as fórmulas filosóficas, Maingueneau recorre a um trecho de Duas fontes da moral e da religião, de Bergson ${ }^{5}$, mostrando as indicações textuais para que a sequência seja destacada: ela ocupa a posição final de um capítulo de uma obra, apresenta uma autonomização enunciativa, e é introduzida pelo metadiscurso. Algumas partes da sequência estão, inclusive, em itálico, reforçando a propensão ao destacamento. Marcações como essas sinalizam que um enunciado específico do parágrafo é candidato ideal à circulação autônoma.

Essas observações evidenciam que, tanto nas máximas heroicas quanto nas fórmulas filosóficas, opera-se, em relação aos demais enunciados do texto, a sobressalência de uma sequência específica, que ocorre "pela condensação semântica que ela implica, associada a uma estrutura de significante pregnante" (MAINGUENEAU, 2004, p. 81).

Até aqui, em Citação e destacabilidade, a reflexão visava a dar conta do fato de que, nos textos, frequentemente são identificados enunciados salientes que ganham vida independente e que funcionam como resumos de doutrinas ou como sentenças de força moral. Por entender que o fenômeno da destacabilidade não se restringe aos textos eruditos, Maingueneau estende a observação da sobressalência para os enunciados em circulação na mídia porque esse fenômeno aparentemente se assenta no próprio funcionamento desse campo: profissionais da comunicação - jornalistas, assessores de imprensa, etc. - estariam familiarizados com procedimentos que situam enunciados em posições textuais privilegiadas de forma que eles possam ser facilmente identificados como destacáveis, permitindo a produção de títulos, intertítulos e legendas de fotos.

Com a indicação dos fragmentos que devem ser retomados, alguns enunciados se tornariam slogans ${ }^{6}$ de intensa circulação nos veículos de informação, seja na televisão ou no rádio. Assim, a partir de exemplos que demonstram a autonomia das fórmulas e das máximas heroicas, Maingueneau (2004) introduz a noção de sobreasseveração, a qual caracteriza um enunciado:

\footnotetext{
${ }^{4}$ As sentenças são: "Para quem vinga seu pai, não há nada impossível", e "A coragem não espera a idade".

${ }^{5}$ A sequência examinada é a seguinte: "Ao contrário, tudo se esclarece quando se vai buscar, além das manifestações, a própria vida. Atribuamos então à palavra biologia o sentido bem compreensível que ela deveria ter, que ela assumirá talvez um dia, e digamos, para concluir, que toda moral, pressão ou aspiração é de natureza biológica". Maingueneau (2004) utiliza itálico no enunciado final para sinalizar que ele se situa em posição de destaque textual.

${ }^{6}$ Com o desenvolvimento da teoria, os slogans são considerados uma família do sistema de particitações.
} 
a) Relativamente breve e de estrutura pregnante no plano do significante e/ou do significado;

b) Em posição relevante, em particular no final ou no começo do texto;

c) Com temática relaciona ao intuito do gênero do discurso;

d) Com capacidade de amplificação da figura do enunciador.

Após terem sido elencadas as características de um enunciado sobreasseverado, são apresentados inúmeros exemplos das diversas formas de exploração desse fenômeno na mídia impressa francesa e brasileira. Nessa compilação ${ }^{7}$, há casos em que a passagem do texto-fonte ao paratexto implica alterações no enunciado; há outros em que, mesmo quando o segmento atende às características da sobreasseveração, ele não está necessariamente fadado ao destacamento, apesar da propensão para tanto.

Na tentativa de chegar a um consenso sobre o funcionamento do destacamento e da sobreasseveração, Maingueneau (2004) propõe três distinções. A primeira é quanto ao tipo de sobreasseveração. No caso de enunciados em que há marcação apropriada para o destacamento, chama-se sobreasseveração pretendida; quando os enunciados forem efetivamente destacados de um texto, fala-se de sobreasseveração derivada. Decorrente da sobreasseveração pretendida, a forma derivada se desdobra em duas subclassificações a depender da autonomização dos enunciados: há, de um lado, o grupo dos chamados enunciados autonomizados, que, em consequência de uma sobreasseveração forte, rompem com o texto de origem; e, de outro, o grupo dos enunciados não autonomizados, que circulam próximos do texto fonte e são resultantes de uma sobreasseveração fraca. Finalmente, a terceira distinção se efetiva no interior da sobreasseveração fraca: opõemse os enunciados destacados de primeiro grau aos de segundo grau, aqueles que são resultado de uma extração anterior, sob forma de citação.

Estas distinções foram organizadas na Figura 1:

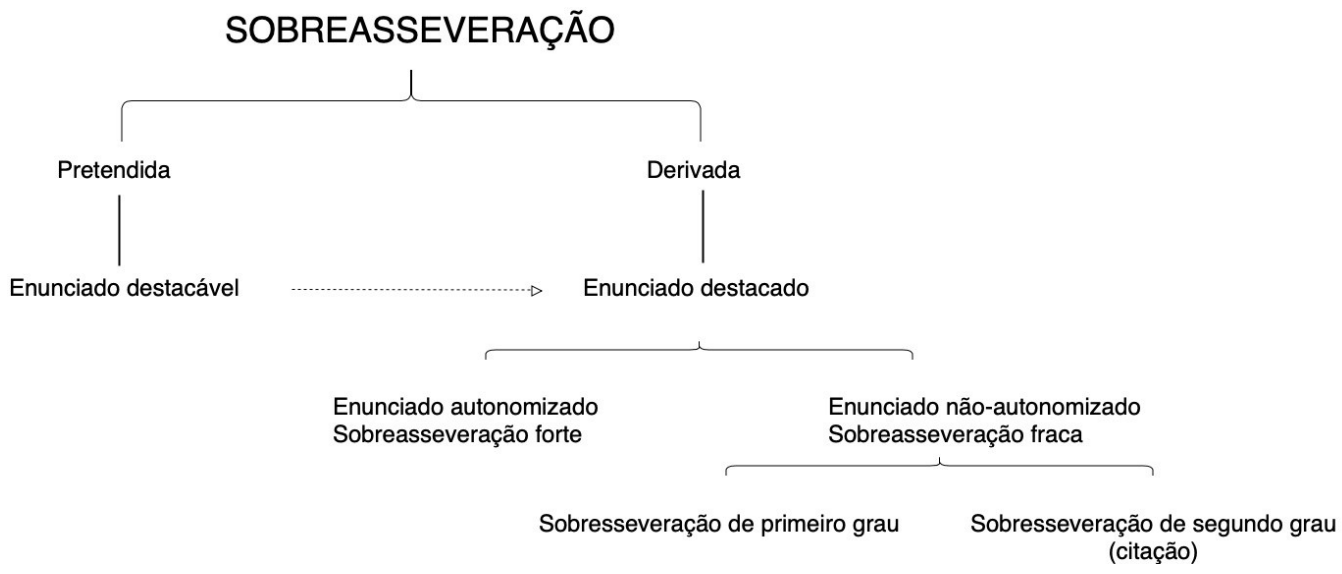

\section{Figura 1 - Tipos de sobreasseveração}

Fonte: Elaborado a partir de Maingueneau (2004).

\footnotetext{
${ }^{7}$ Os exemplos apresentados foram extraídos de jornais distribuídos gratuitamente na França (Métro e 20 Minutes) e de veículos tradicionais franceses (Tele Star, Le Monde e Libération) e brasileiros (UOL e Veja).
} 
A imagem permite visualizar as definições preliminares para sobreasseveração e favorece o acompanhamento da linha de raciocínio do autor à época. Na figura, a linha partilhada, que sai da entrada "enunciado destacável" em direção a "enunciado destacado", reforça a ideia de que a sobreasseveração pretendida é apenas uma propensão ao destacamento, não uma causa incondicional.

Nesse primeiro texto, observa-se que sobreasseveração parece confundir-se com aforização, noção hoje muito bem definida. A própria tradução do título original para português do Brasil dá indícios de que as terminologias eram intercambiáveis (a palavra surassertion do título francês aparece como destacabilidade, em português). Tal percepção se sustenta também no que se pode inferir do seguinte trecho: "A autonomização da sobreasseveração em relação ao texto de origem vai mais longe quando existe uma transformação do enunciado" (MAINGUENEAU, 2004, p. 86). Ou seja, a sobreasseveração e a autonomização são tratadas como processos equivalentes.

Além disso, a bibliografia especializada no Brasil, publicada a partir desse primeiro texto, registra que: "os casos de destacabilidade são extremamente numerosos e aumentam com o crescimento e a diversificação da mídia. [...] Maingueneau qualifica esse processo como sendo de sobreasseveração" (POSSENTI, 2008, p. 67, grifo no original), o que também corrobora o entendimento de que havia sobreposição das noções de enunciado sobreasseverado e enunciado destacado.

A estabilidade terminológica vai sendo construída com o desenvolvimento da teoria. Todavia, esse uso intercambiável inicial trouxe consequências para a definição dos conceitos em torno da aforização, no que tange inclusive ao sujeito enunciativo desse regime, como será abordado mais adiante. Neste ponto da pesquisa, importa questionar: considerando a desconformidade entre enunciado destacável e enunciado destacado, seria possível manter a noção de sobreasseveração para os dois casos?

\section{DA SOBREASSEVERAÇÃO PARA A AFORIZAÇÃO}

Ainda sem desenvolver com profundidade, os parágrafos finais de Citação $e$ destacabilidade apontam que não se deve confundir uma lógica de "sobreasseveração que faz aparecer uma sequência sobre um fundo textual - e uma lógica de aforização (para ser exato, um destaque aforizante) que implica um tipo de enunciação totalmente diferente" (MAINGUENEAU, 2004, p. 92).

Nos dois textos seguintes - De la surassertion à l'aphorisation, e L'énonciation aphorisante, publicados em 2006 e em 2007, respectivamente -, Maingueneau define os limites enunciativos do que é destacável e do que é destacado, rejeitando a relação de continuidade entre a sobreasseveração e a destacabilidade: o enunciado sobreasseverado implicaria um certo locutor e o enunciado destacado implicaria outro, ainda que essas duas instâncias sejam ou não indexadas pelo mesmo nome próprio. A solução encontrada é a distinção de duas lógicas: a da sobreasseveração (já apresentada no texto de 2004) e a do destacamento aforizante (desenvolvida nesses dois textos). 
Para desenvolver a lógica aforizante, Maingueneau $(2006,2007)$ segue a lacuna deixada por um estudo de Benveniste, sobre a qual serão apresentados alguns aspectos, frisando o que convier para os fins deste artigo. Ao examinar o indo-europeu, Benveniste mostra que as frases nominais e sua respectiva contrapartida com cópula ${ }^{8}$ constituem dois tipos distintos de enunciação. Nessa língua, as frases nominais são um enunciado assertivo finito, paralelo na sua estrutura a qualquer outro que tenha a mesma função sintática; são sequências compostas igualmente por dois elementos: um implícito e invariante, que dá ao enunciado força de asserção, e outro, variável e explícito, que pertence à classe morfológica dos nomes. Como o elemento assertivo dessa estrutura da frase não é susceptível às determinações que a forma verbal tem em si - as marcas de tempo, de pessoa, de número, por exemplo -, a "asserção terá esse caráter próprio de ser intemporal, impessoal, não modal, em suma, de ter por objeto um termo reduzido apenas ao seu conteúdo semântico.” (BENVENISTE, 1950, p. 171).

Benveniste observa também que, no grego antigo e no latim, a frase nominal não é empregada para descrever um fato na sua peculiaridade porque propõe uma relação intemporal e perpétua que visa a convencer como uma "verdade geral". Essa tese é validada por um estudo de corpus que compara um texto poético - as Píticas, de Píndaro - e uma prosa narrativa - a História, de Heródoto. No poema, é grande o número de frases nominais, mas elas não aparecem em situações ocasionais, apenas nas passagens em que se profere sequências de valor permanente. Na prosa narrativa, apesar de aparecerem em menor número, as ocorrências se dão em discursos reportados para enunciar uma asserção do tipo "proverbial". Na obra de Homero a frase nominal tampouco aparece nas sequências narrativas, e sim naquelas em que se exprimem asserções aptas para servir de referência ou para quando se quer criar uma convicção.

Segundo Benveniste, fica evidente que a frase nominal "tem valor de argumento, de prova, de referência. É introduzida no discurso para agir e convencer, não para informar. É, fora do tempo, das pessoas e da circunstância, uma verdade proferida como tal" (BENVENISTE, 1950, p. 179). Mesmo não se voltando diretamente para a textualidade tampouco para a destacabilidade, Benveniste torna explícita uma lacuna: as frases sem verbo aparecem em um texto, mas, por expressarem uma verdade absoluta, aspiram a sair dele. No prolongamento dessa perspectiva, inscreve-se o destacamento aforizante tendo em vista que as frases nominais revelam que, na dimensão constitutiva da enunciação, existe um regime enunciativo específico.

Ampliando essa linha de pensamento para a reflexão sobre as fórmulas sentenciosas, as máximas heroicas, e a proliferação de enunciados generalizantes produzidos pela máquina midiática, Maingueneau $(2006,2007)$ entende que a destacabilidade é apenas parte de um processo que engloba toda a dimensão constitutiva da enunciação. Por isso, é necessário distinguir dois regimes enunciativos: a enunciação textualizante e a enunciação aforizante. A primeira está relacionada ao horizonte dos gêneros do discurso; a segunda, ao contrário, rompe com essa lógica.

\footnotetext{
${ }^{8}$ Como exemplo, Maingueneau (2006) utiliza a frase nominal em latim Homo homini lupus e Homo homini lupus est (homem lobo próprio do homem e homem é o lobo próprio do homem, respectivamente).
} 
Para iniciar a definição do estatuto da enunciação aforizante, Maingueneau (2006, 2007) toma como exemplo a frase "Eu me acho linda", atribuída a Preta Gil, e que foi destacada de uma fala pública da cantora e divulgada na seção Veja Essa, da revista Veja. Esse enunciado aforizado constrói outra cena dentro de outro gênero, diferente daquele no qual foi originalmente produzido, evidenciando que, apesar de não entrar na lógica de um gênero do discurso, a aforização não pode ser proferida fora dele. Entre a aforização e o texto que a acolhe, há uma tensão resultante da "pretensão ilocutória ligada à aforização, de ser uma fala absoluta, sem contexto, convocada dentro de um texto, que não é absoluto (MAINGUENEAU, 2006, p. 161, grifo no original). Assim, entre um enunciado aforizado e um texto, não há diferença de tamanho, mas de ordem, pois referese a uma profunda desconexão entre aquilo que pertence a um tipo de gênero discursivo e aquilo que ultrapassa qualquer tipo.

Ao distinguir dois regimes enunciativos, Maingueneau $(2006,2007)$ reorganiza a nomenclatura do texto de 2004: o que antes era denominado "sobreasseveração derivada" passa a ser entendido como aforização, termo que se refere tanto ao regime enunciativo quanto ao próprio enunciado destacado. Em De la surassertion à l'aphorisation e em $L$ ' énonciation aphorisante, fica estabelecido que a sobreasseveração corresponde especificamente aos "enunciados que são modulados pelo locutor de maneira a ser apresentados como destacáveis" (MAINGUENEAU, 2006, p. 116), passando a ser entendida como a demarcação da destacabilidade de uma sequência em um texto.

Notadamente no trabalho de 2007, reforça-se a diferença entre aforização e sobreasseveração a partir da comparação dos enunciados no paratexto com os enunciados do texto de origem. Evidencia-se que, nas produções midiáticas, o enunciado destacado tende a sofrer alterações para entrar no regime aforizante. Dos vários exemplos que sustentam essa constatação, serve de apoio o trecho de duas entrevistas ${ }^{9}$ e seus respectivos paratextos, reproduzidos abaixo:

\begin{abstract}
[paratexto] 'Eu sou muito ligado em sexo'
[entrevista] A imprensa rotula você de 'intelectual'. Você não seria antes rock 'n roll?

Eu não penso em sê-lo no sentido tradicional, mas há alguma coisa de muito físico e de muito sexual em um guitarrista. Nesse sentido, sim, eu sou muito rock ' $\mathrm{n}$ roll. As pessoas pensam que, porque você intelectualiza seu trabalho, você não pode ser alguém muito físico. Os dois não são antagônicos. Eu sou e eu sempre fui alguém muito ligado em sexo.
\end{abstract}

\title{
$[\ldots]$
}

\section{[paratexto] 'Para durar nessa profissão, é preciso ser forte'}

As pessoas não se dão conta, elas têm a impressão de que, quando a gente é conhecida, a gente chegou lá. É difícil durar. É preciso ser muito forte psicologicamente. Às vezes sou, às vezes, não (MAINGUENEAU, 2007, p. 158, grifados no original) ${ }^{10}$

\footnotetext{
${ }^{9}$ A entrevista de Chalay foi publicada na revista Jalouse, n. 58, de março de 2003; e a entrevista de BruniTedeschi, no Le Figaro, de 2 de outubro de 2004.

${ }^{10}$ Como o original está em francês, recorre-se à tradução registrada em Maingueneau (2013).
} 
Os dois trechos foram extraídos de entrevistas: a primeira é com o design de moda turco Hussein Chalayan; e a segunda é com a apresentadora de televisão monegasca Alexandra Kazan. Em ambos os trechos destacados houve supressão de elementos na passagem ao paratexto, o que impede de afirmar que se trata exatamente do mesmo enunciado. $\mathrm{Na}$ entrevista de Chalayan, a frase se encontra sobreasseverada - está em posição final e, pela construção sintática simétrica, possui forte organização interna e, ainda assim, sofre alteração. O enunciado de Alessandra Kazan é ainda mais emblemático: o enunciado que apresenta estrutura sintática simétrica - "às vezes sou, às vezes, não" - não é o que foi alçado ao título. O enunciado original apresenta movimento argumentativo repartido em diversas frases, e, chega à aforização a partir da transformação em uma frase única generalizante. É como se essa alteração lapidasse a autonomia do enunciado originalmente não sobreasseverado.

Desse tipo de divergência entre o enunciado de origem e o enunciado destacado depreende-se que a sobreasseveração e o destacamento são dois fenômenos distintos, a saber: "a sobreasseveração, que prepara um fragmento destacável, é um fenômeno que está relacionado ao funcionamento textual, enquanto que o enunciado destacado implica um regime enunciativo específico, não textual, o qual designaremos pelo termo aforização" (MAINGUENEAU, 2007, p. 159, tradução nossa, grifo no original) ${ }^{11}$. Dessa forma, na dimensão constitutiva da enunciação, ocupam lugares distintos a sobreasseveração e a aforização: esta é o resultado do destacamento; aquela é a demarcação de um enunciado como um forte candidato à destextualização, sendo apenas uma modulação enunciativa para formatar um fragmento como destacável, não implicando que um enunciado com essas propriedades seja efetivamente destacado. Quanto à independência do enunciado aforizado em relação ao texto-fonte, essa questão pode ser avaliada como resultado de um destacamento fraco ou de um destacamento forte (MAINGUENEAU, 2007), mantendo as delimitações estabelecidas em Citação $e$ destacabilidade.

Nos textos de 2006 e de 2007, fica estabelecido que, por tratarem de aspectos linguísticos relacionados à amplificação de certas sequências de um texto, a sobreasseveração se situa no regime textualizante, e a aforização corresponde tanto ao processo quanto ao produto do regime aforizante (os enunciados autônomos, resultantes de uma sobreasseveração ou não). Pela enunciação aforizante, são produzidos dois tipos de aforização: um tipo que engloba os enunciados autônomos por natureza, que possuem valor generalizante, e são atribuídos a uma instância anônima; e outro correspondente aos enunciados não necessariamente generalizantes, destacados de um texto e atribuídos aos indivíduos em geral indexados por um nome próprio.

A terminologia para esses dois grupos sofre modificações, ainda que conserve as mesmas definições: enunciado autonomizado e enunciado não autonomizado (MAINGUENEAU, 2004); enunciados originais e enunciados derivados (MAINGUENEAU, 2006, 2007), enunciados destacados por natureza e enunciados destacados de um texto (MAINGUENEAU, 2010, 2012a), e, finalmente, na terminologia mais atual, aforizações primárias e aforizações secundárias (MAINGUENEAU, 2012b, 2014).

\footnotetext{
${ }^{11}$ No original : "La surassertion, qui pose un fragment comme détachable, est un phénomène qui relève du fonctionnement textuel, alors que l'énoncé détaché implique un régime énonciatif spécifique, non textuel, que nous désignons par le terme aphorisation".
} 


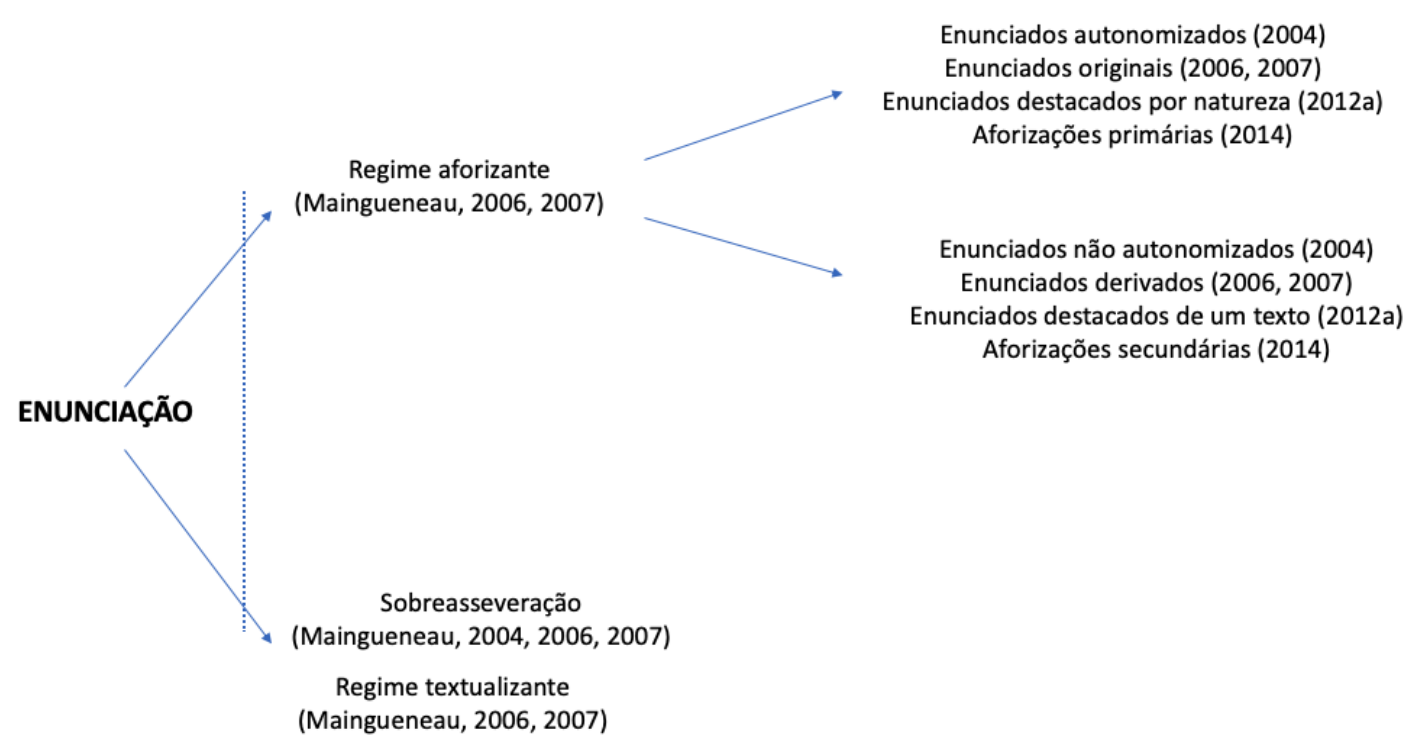

Figura 2 - Sobreposição terminológica na construção da teoria do regime aforizante Fonte: Elaborado pelo autor (2019).

Para explicitar o percurso das discussões sobre o destacamento, especialmente no que se refere à distinção entre sobreasseveração e aforização, redesenha-se o quadro elaborado no início desta seção, evidenciando a diversidade terminológica registrada nos textos deste levantamento bibliográfico. A figura 2 distingue os dois regimes enunciativos: o regime textualizante e o regime aforizante. Nas setas que saem do regime aforizante, evidenciam-se os tipos de aforizações sob as mais diversas nomenclaturas, cunhadas ao longo do desenvolvimento da teoria. Próxima do regime textualizante, está disposta a sobreasseveração porque é nos limites do texto que podem aparecer as marcas de destacabilidade. A linha pontilhada entrecruza os dois regimes, indicando a relação paradoxal entre eles: pelo destacamento, um enunciado escapa de um texto, mas, quando aforizado, só pode circular se estiver em um gênero.

\section{AFORIZADOR}

A definição de que há enunciados que são produzidos pela enunciação aforizante exige que se estabeleça o estatuto pragmático desse regime enunciativo. $\mathrm{O}$ sujeito da enunciação aforizante chama-se aforizador. Na seção anterior, foi explicitado que a atividade de fala se desenvolve segundo, pelo menos, dois regimes enunciativos: o textualizante, cujos modos de subjetivação são determinados pelos gêneros do discurso; e o aforizante, pelo qual o dizer se apresenta como uma proposição incontestável, relacionada a um sujeito de pleno direito, não assujeitado ao jogo das interações discursivas. Como entre esses dois regimes enunciativos não há uma diferença de tamanho, mas de ordem, essa distinção traz consequências à noção de sujeito da enunciação, àquele que diz eu no enunciado: no regime textualizante, o sujeito é determinado por modos de subjetivação relacionados a um gênero do discurso; no regime aforizante, trata-se de um sujeito de pleno direito que se dirige a um público 
indeterminado, estando ambos situados em nível diferente daquele imposto pelas fronteiras do gênero.

Retomando o levantamento bibliográfico, pode-se afirmar que indícios da definição desse estatuto pragmático já são observados em Citação e destacabilidade. Com o objetivo de mostrar que o regime aforizante não é um fenômeno periférico reservado à imprensa popular, Maingueneau constrói um corpus heterogêneo composto por uma variedade de frases coletadas nas mais diversas fontes, proferidas por personalidades políticas e por celebridades que foram postas a circular pela mídia impressa francesa tradicional e popular, bem como pela mídia impressa brasileira. Em um dos materiais, o autor ilustra a diferença entre enunciado-fonte e enunciado destacado com a manchete da entrevista de Oliver, primeiro vencedor do reality show "Le Bachelor" e de Alexandra, sua companheira. A posição superior da página é ocupada por um enunciado atribuído ao casal. O texto de origem, porém, registra outra versão, apenas com Oliver como locutor ${ }^{12}$.

Àquela altura das reflexões, ainda em estágio inicial, importava garantir um estatuto diferenciado à sobreasseveração, que evidenciasse a transformação de enunciado-fonte para o enunciado destacado. Apesar de Maingueneau já observar a dissonância entre locutor efetivo e esse mesmo locutor enquanto fonte de um enunciado destacado, especialmente quando resultante de um agenciamento da máquina midiática, essa questão não é desenvolvida.

Insistindo na pertinência de estabelecer o estatuto pragmático da aforização, Maingueneau retoma praticamente o mesmo corpus construído em Citação $e$ destacabilidade para, em Les énoncés détachés dans la presse écrite, se empenhar na determinação da figura do enunciador nesse regime. O ponto de partida é a percepção de que, apesar de o funcionamento das mídias favorecer a construção de sequências formatadas para serem destacadas, o jornalista pode operar o destacamento de diversas fontes e fabricar "pequenas frases", manipulando um enunciado que pode implicar a não coincidência entre locutores do enunciado-fonte e do enunciado destacado. Como resultado do destacamento, "produz-se uma discrepância entre o locutor efetivo do enunciado e esse mesmo locutor como fonte do enunciado destacado pela máquina midiática" (MAINGUENEAU, 2006, p. 116) ${ }^{13}$.

Nesse mesmo texto, Maingueneau retoma as propriedades das frases nominais, desta vez enfatizando que, nelas, a imbricação entre as dimensões referenciais, modais e textuais produz um enunciado que, ao mesmo tempo: i) é desembreado, ou seja, apresenta-se como se estivesse isolado da situação de enunciação; ii) é revestido por uma autoridade cuja responsabilidade é atribuída a uma instância que não coincide com o produtor empírico do enunciado; e iii) não pertence a um texto (provérbios, adágios, etc.).

Parece claro que o intuito de retomar as frases nominais é o de firmar teoricamente o lugar em que se sustentaria a proposta de desenvolvimento de um regime enunciativo diferente do textualizante. Para Maingueneau, o regime aforizante enfrenta o entrave de uma definição precisa, já que, numa sociedade dominada pela oralidade, a aforização

\footnotetext{
${ }^{12} \mathrm{Na}$ entrevista, Oliver, o vencedor do programa, diz: "Se, algum dia, a coisa não estiver bem entre nós, não vamos esconder". No título da matéria, no entanto, aparece: "Oliver e Alexandra - Se a coisa não for bem entre nós, vamos contar para vocês” (MAINGUENEAU, 2004, grifo no original).

${ }^{13}$ No original : "Il se produit dès lors un décalage essentiel entre le locuteur effectif et ce même locuteur en tant qu'il est la source d'un énoncé détaché par la machine médiatique”.
} 
manteria relações privilegiadas com a memória, com as generalizações, com as formas poéticas e com os gêneros sentenciosos. No caso da sociedade contemporânea, dominada pelas mídias audiovisuais, as operações de recorte e re-textualização de enunciados entram em primeiro plano. Mesmo em se tratando de relações distintas em cada um dos casos, o tipo de enunciação é o mesmo: à maneira do que acontece com as frases nominais, nas aforizações "tem-se o dizer verdadeiro de um Sujeito pleno que se conjuga em uma unidade imaginária de uma asserção autônoma" (MAINGUENEAU, 2006, p 118) ${ }^{14}$.

Ainda em Les énoncés détachés dans la presse écrite, Maingueneau começa a delinear o estatuto do sujeito da enunciação do regime aforizante, sustentando-se na percepção de que a aforização tensiona o assujeitamento dos enunciados a um gênero do discurso, pois o enunciado aforizado, ao mesmo tempo que pertence a um tipo de discurso, também ultrapassa qualquer um deles. Como são enunciados destacados, as aforizações são marcadas pelo apagamento do cotexto, e instauram um novo compromisso ilocucionário, não definido especificamente pelos horizontes do gênero do discurso. É graças a esse rompimento que o sujeito da enunciação aforizante "afirma uma verdade refletida, subtraída de negociação, expressa uma totalidade: uma doutrina filosófica, uma concepção de existência" (MAINGUENEAU, 2006, p. 119) ${ }^{15}$.

$\mathrm{Na}$ lógica da aforização, pela qual são produzidos enunciados autônomos geralmente constituídos por uma única frase, a figura do enunciador "não somente diz, mas mostra o que diz" (MAINGUENEAU, 2014, p. 28). Trata-se, portanto, de um sujeito de enunciação que apresenta a força de uma posição exemplar, de um posicionamento irrepreensível em relação ao mundo. O aforizador se mostra como um homem autorizado, que exprime uma posição de mundo e que estabelece valores, sobre os quais não cabe discussão ou contestação.

Em L'énonciation aphorisante, fica estabelecido que cada tipo de aforização corresponde a um tipo de enunciador diferente. Para os enunciados sentenciosos (aforizações primárias), atribui-se a responsabilidade do dizer a um hiperenunciador ${ }^{16}$; para os enunciados pessoais, a responsabilidade é atribuída aos indivíduos em geral indexados por um nome próprio. Entende-se também que "a enunciação aforizante institui uma cena de fala onde não há interação entre dois protagonistas situados no mesmo plano: a instância responsável pela enunciação aforizante fala de outro lugar" (MAINGUENEAU, 2007a, p. 161, tradução nossa) ${ }^{17}$. Essa constatação é evidente para as aforizações primárias, e no caso das secundárias também é significativa: o trabalho de destacamento de enunciados cria um efeito de que apenas um número restrito de indivíduos sobressalentes de uma coletividade é levado a uma cena de fala autorizada, a ordem outra de importância acessível apenas a locutores autorizados.

${ }^{14}$ No original: "[...] c'est le dire vrai d'un Sujet plein qui se rassemble dans l'unité imaginaire d'une assertion autonome."

${ }^{15}$ No original: "ils sont censés énoncer une vérité réfléchie, soustraite à la négociation, l'expression d'une totalité: une doctrine philosophique, une conception de l'existence".

${ }^{16}$ Nesse texto, associa-se o hiperenunciador às aforizações primárias. No desenvolver da teoria sobre o regime aforizante, essa figura enunciativa torna-se nuclear para identificar um sistema específico de aforizações, as particitações. Ver Maingueneau (2004b e 2011).

${ }^{17}$ No original: "L'énonciation aphorisante institue une scène de parole où il n'y a pas d'interaction entre deux protagonistes placés sur un même plan : l'instance responsable de l'énonciation aphorisante se tient dans un ailleurs" (MAINGUENEAU, 2007, p. 161). 
Essa discussão se estende em Aforização: enunciados sem texto?, quando Maingueneau defende que a aforização faz emergir um modo distinto de subjetivação, diferente do regime textualizante em que formas de subjetividade variam de acordo com o suporte e com os modos de circulação, impostos propriamente pela escrita. No caso da aforização, o enunciado pretende exprimir o pensamento do locutor não submetido a um jogo de linguagem pois "pretende escapar do fluxo de comunicação, ser pura fala" (MAINGUENEAU, 2010, p. 14).

Nesses dois últimos trabalhos referidos, o autor chama especial atenção à frequente presença de fotos de rostos articuladas às aforizações, particularmente na mídia impressa, em que a fala de determinados locutores é pinçada do cotexto e alçada a um espaço de destaque junto com a fotografia deles, atestando a plena responsabilidade do dito a um sujeito único. A questão do rosto será tratada um pouco mais adiante; não obstante, urgem algumas palavras sobre o que parece ser o ponto crucial para definir o sujeito da enunciação aforizante: a responsabilidade enunciativa.

A depender do regime, atribui-se responsabilidade a instâncias distintas, ainda que elas possam corresponder ao mesmo sujeito empírico. Para distinguir essas instâncias enunciativas nos dois regimes, parte-se da responsabilidade enunciativa no regime textualizante, em que, de maneira geral, o indivíduo que fala é também aquele que se apresenta como responsável pelo enunciado. Nesse regime, o sujeito realiza duas operações: situa-se como fonte de ancoragem dos embreantes para a situação de enunciação, e também apresenta o enunciado como verdadeiro, garantindo-lhe a autenticidade.

Por vezes, essas duas dimensões são inseparáveis - o sujeito da enunciação textualizante é tanto o ponto de ancoragem das operações referenciais quanto a fonte das operações modais -, e aquele que fala coincide com aquele responsável pelo dito. Todavia, há casos em que essa dupla equivalência não é insuspeita: por exemplo, quando um sujeito cita as palavras de outrem, ele pode estar se eximindo de responsabilidade; quando uma palavra é aspeada em um texto, sinaliza-se, no nível lexical, um afastamento do dito.

Esse movimento enunciativo permeia a problemática da polifonia, desenvolvida por Bakhtin, segundo a qual nos textos, especialmente os literários, há várias vozes que falam simultaneamente sem que uma dentre elas seja preponderante. Operando em um quadro mais restritivo, Ducrot (1987) leva a polifonia para a linguística e estabelece distinções entre sujeito falante, locutor e enunciador. O primeiro corresponde ao ser empírico que produziu o enunciado; o segundo é aquele a quem se pode atribuir a responsabilidade do enunciado; e o terceiro é o sujeito enunciativo cujo ponto de vista determina a forma como os acontecimentos são apresentados.

Para Maingueneau (1994, 2013), as fronteiras entre essas três instâncias enunciativas são confusas e pouco operacionais, pois reforçam o tratamento privilegiado da dimensão referencial da linguagem, negligenciando a dimensão modal estabelecida pelo enunciador com sua própria enunciação. No entender dele, essa discrepância pode ser resolvida se for feita a distinção entre a instância que enuncia e a instância que se apresenta como responsável pelo dito: "O produtor é quem elaborou materialmente o enunciado, enquanto o locutor é quem realiza a enunciação, é aquele a quem se referem 'eu', 'meu', etc. e que se encontra em um lugar que pode ser designado como 'aqui' (MAINGUENEAU, 2013, p. 166-167, grifo nosso). 
Ao distinguir produtor e locutor, Maingueneau igualmente estabelece, de certa forma, um critério para que se possa atribuir a um sujeito a responsabilidade enunciativa: é aquele que encena ser a fonte do dizer. Por esse ângulo, pode-se atribuir ao locutor a responsabilidade pelos enunciados por ele proferidos, e, mesmo quando outras vozes são encenadas - a voz daquele a quem se dirige, a voz de qualquer indivíduo ou grupo de indivíduos em terceira pessoa, ou a voz da coletividade -, o locutor é aquele que se apresenta como responsável por elas. Essa encenação do dizer pode também provocar o efeito contrário, o de se eximir da responsabilidade, quando, por exemplo, o locutor evoca um ponto de vista e o refuta.

Esse "orquestramento" de vozes é mais facilmente percebido no caso dos discursos citados, em que falas são atribuídas a outras instâncias que não a do locutor, ou no caso do discurso direto, em que aquele que cita simula as palavras do locutor citado. Ainda, pelo discurso indireto, o locutor pode reformular o enunciado original em favor de seus propósitos. No caso dos discursos relatados, a responsabilidade enunciativa depende do próprio movimento enunciativo mobilizado pelo locutor. Este, ao evocar um ponto de vista, pode tanto recusá-lo quanto aderir a ele, ou seja, "quando um locutor fala, ele não se contenta em expressar suas próprias opiniões; ao contrário, ele faz ouvir diversas vozes, mais ou menos claramente identificadas, em relação às quais ele se situa" (MAINGUENEAU, 2013, p. 163).

Tratar da lógica da citação no regime textualizante implica discutir responsabilidade enunciativa na perspectiva da relação entre dois acontecimentos enunciativos mobilizados pela retomada de falas de outrem na enunciação. Essa é uma questão complexa, e desenvolvê-la com mais afinco significa fugir do escopo deste estudo; foi trazida à baila porque esses enunciados do discurso relatado são, em certo nível, uma forma de destacamento cujas consequências criam uma tensão quanto à responsabilidade do dizer. Em todo caso, essa zona de tensão é criada quando o enunciado de outrem é deslocado e situado em um novo contexto. Mesmo no caso do discurso direto em que a citação é apresentada como uma exata reprodução das palavras do enunciador citado, o enunciado não necessariamente corresponde às falas efetivamente pronunciadas, mas a responsabilidade por ele é atribuída a um único sujeito da enunciação.

A questão da responsabilidade enunciativa permeia toda a progressão do trabalho de construção teórica sobre o regime aforizante, inclusive quando havia sobreposição terminológica de sobreasseveração e aforização, mencionada na primeira seção deste texto. Quanto aos efeitos da questionável decisão de traduzir surassertion para "destacabilidade", o texto original de 2004 traz registrado o termo "sobreasseverador" (tradução de surasserteur, do original) que, à época, se referia aos casos em que o locutor do destacamento "não pode coincidir com o locutor do texto de origem" (MAINGUENEAU, 2004, p. 89).

Essa escolha terminológica original parece recuperar aspectos teóricos de outras definições, a de "asserção" (assertion) e a de "asseverador" (asserteur). No Dicionário de Análise do Discurso, organizado em parceria com Charaudeau, o termo "asserção" aparece para designar "todo enunciado que contém uma certa visão de mundo, quer se apresente sob forma positiva, negativa, hipotética ou condicional. A asserção diz respeito ao próprio fato de pôr em relação elementos para dizer alguma coisa sobre o mundo" (CHARAUDEAU, 2018, p. 68). A responsabilidade enunciativa para esse tipo de enunciado é atribuída a um "asseverador” (MAINGUENEAU, 1994, 2013). 
Considerando a propriedade de produzir uma fala que, mais do que a asserção, se apresenta como incontestável, longe das negociações, o destacamento instaura uma instância enunciativa de Sujeito de pleno direito, acima do asseverador. Daí o sufixo sur (acima de) para indicar esse posicionamento em nível superior. Ocorre que, aparentemente, quando da distinção dos dois regimes enunciativos e da instituição da sobreasseveração como possibilidade exclusiva no nível da textualização, a noção de "sobreasseverador" como o sujeito enunciativo do destacamento se tornou inócua, uma vez que os papéis enunciativos, nesse regime, são determinados pelo gênero, sem rompêlo. As propriedades então conferidas ao "sobreasseverador" são incorporadas à noção de "aforizador", a quem se pode atribuir a responsabilidade enunciativa do regime aforizante.

Os textos publicados entre 2010 e 2012 elucidam as especificidades dos diferentes modos de subjetivação correspondentes a cada um dos dois regimes enunciativos. Em Aforização: enunciados sem texto?, Maingueneau mostra que, no regime textualizante, especialmente em se tratando do texto escrito, as relações são estabelecidas entre um locutor que fixa a si e a outro(s) destinatário(s), não havendo a possibilidade de troca, pelo menos imediata, de papéis entre ambos. Nesse regime, predomina uma organização interna que tende a estratificar planos enunciativos - figuras dos enunciados, índices de polifonia, planos textuais, embreantes, etc., o sujeito da enunciação é "descentrado", e compartilha a responsabilidade do dizer, que pode ser, inclusive, negociada. Na lógica da aforização, ao contrário, o enunciado tende à homogeneidade por ser uma "forma de dizer puro, quase próxima de uma consciência" (MAINGUENEAU, 2010, p. 14). Fora das coerções dos gêneros, o sujeito não é apreendido por papéis. Dado o caráter fundamentalmente monologal desse regime enunciativo, o aforizador é uma instância centralizadora, que exerce toda a plenitude do dizer.

Essa constatação é reforçada em Enunciação ligada, enunciação desatada, quando Maingueneau direciona a atenção para um artigo publicado no Le Monde em que um indivíduo designado por um nome se apresenta duas vezes, uma no enunciado do texto e outra no enunciado destacado. A essas duas apresentações do mesmo ser empírico corresponderiam dois estatutos distintos: o de locutor, inscrito em uma situação de comunicação imposta pelo texto, e o de aforizador, inscrito fora dessa situação de comunicação. Essa observação sobre a publicação do jornal francês torna evidentes, pelo menos, dois aspectos constitutivos do regime aforizante, ao passo que a frequência de ocorrências semelhantes denota não ser esse um caso isolado. $O$ primeiro aspecto relaciona-se ao aforizador, que por surgir em consequência de um destacamento, cria um paradoxo. Apesar de se apresentar como sujeito falante por excelência, essa posição enunciativa só pode ser alcançada pela intervenção de um terceiro. Logo, "é na medida em que, como numa cena de teatro, a instância que sustenta a palavra é posta em espetáculo por um terceiro que ela pode enunciar com majestade. A palavra deve ser retomada para poder ser plenamente dita" (MAINGUENEAU, 2012a, p. 18).

O segundo aspecto constitutivo do aforizador é o do papel desempenhado pela fotografia de rosto que, nas produções midiáticas, regularmente acompanha os enunciados aforizados. Para Maingueneau (2010), o rosto tem três propriedades notáveis: i) identifica o indivíduo como distinto de qualquer outro; ii) é a sede do pensamento; e 
iii) é onde se encontra a boca, fonte da fala. Por esse prisma, ao se articular com o enunciado destacado, a fotografia de rosto autentica a aforização como sendo a fala de um sujeito responsável, sinalizando ser aquela a sua fala. Além disso, o ângulo da fotografia geralmente privilegia o olhar, direcionado a um auditório indeterminado do qual o leitor participa, e faz esconder as mãos, cuja presença indicaria a participação de um alocutário que partilharia o mesmo espaço de interlocução e que, portanto, poderia intervir.

Tanto o enunciado verbal quanto o rosto são resultado de destacamento. A ausência de marcas de um possível alocutário reforça a autonomia e a atemporalidade porque "a aforização, na medida em que exprime esse Sujeito, diz o que é, não no instante, mas na duração atemporal do valor" (MAINGUENEAU, 2010, p. 17).

\section{CONSIDERAÇÕES FINAIS}

O que se percebe, com esse levantamento bibliográfico, é que, bem antes de Les phrases sans texte, a teoria sobre as aforizações derivou da observação primeira de textos da filosofia e do teatro francês. Em seguida, ela foi deslocada para os enunciados em circulação na mídia, campo propício para a destacabilidade, que eleva ao paroxismo a potencialidade desse regime enunciativo. É esse percurso teórico que aparece registrado na obra de 2012, que chegou ao Brasil dois anos depois.

Por algum tempo, as noções de sobreasseveração e de aforização foram usadas de forma intercambiável, até que se distinguisse o limite da textualização, no que concerne às marcas linguísticas da propensão ao destacamento. $\mathrm{O}$ enunciado aforizado, no entanto, apesar de circular em um gênero, rompe com essa lógica.

Além disso, foi identificada certa heterogeneidade de escolhas terminológicas, tanto no original quanto na tradução para o português do Brasil. Essas escolhas, em um primeiro momento, podem ser entendidas como inconsistência teórica. Este texto argumenta em defesa de que a diversidade de terminologias em torno de um mesmo conceito é consequência da construção progressiva das noções que o regime mobiliza, e que isso não enfraquece a base teórica na qual elas foram erigidas; pelo contrário, são as tentativas teóricas que fortalecem a pertinência de uma investigação.

\section{REFERÊNCIAS}

BENVENISTE, E. [1950] A frase nominal. In: BENVENISTE, E. Problemas de linguística geral I. 5. ed. Tradução de Maria da Glória Novak e Maria Luísa Neri. Revisão de Isaac Nicolau Salum. Campinas (SP): Pontes, 2005 (p. 163-182).

CHARAUDEAU, P. Asserção. In: CHARAUDEAU, P.; MAINGUENEAU, D. Dicionário de análise do discurso. 3. ed. São Paulo: Contexto, 2018. p. 67- 68.

DUCROT, O. O dizer e o dito. Campinas (SP): Pontes, 1987.

KRIEG-PLANQUE, A. A noção de "fórmula" em análise do discurso: quadro teórico e metodológico. Tradução de Luciana Salazar Salgado e Sírio Possenti. São Paulo: Parábola, 2010.

MAINGUENEAU, D. L'énonciation en linguistique française. Paris: Hachette, 1994. 
MAINGUENEAU, D. Citation et surassertion. Polifonia, v. 8, n. 8, 2004. Disponível em: http://periodicoscientificos.ufmt.br/ojs/index.php/polifonia/article/view/1124/888. Acesso em 10 de maio de 2019. [Tradução em português: Citação e destacabilidade. Tradução de Roberto Leiser Baronas In: MAINGUENEAU, D. Cenas da enunciação. Org. de POSSENTI, S.; SOUZA-E-SILVA, M. C. P. de. São Paulo: Parábola, 2008 (p. 75-92)]

MAINGUENEAU, D. Les énoncés détachés dans la presse écrite. De la surassertion à l'aphorisation. Revue Tranel (Travaux neuchâtelois de linguistique), v. 44, p. 107-120, 2006. Disponível em : http://doc.rero.ch/record/17519. Acesso em: 30 abr. 2019.

MAINGUENEAU, D. L'énonciation aphorisante. Conferências do V Congresso Internacional da Associação Brasileira de Linguística, Universidade Federal de Minas Gerais: Belo Horizonte, 2007. p. 153-163. Disponível em: shorturl.at/bEMS1. Acesso em: 20 abr. 2019.

MAINGUENEAU, D. Aforização: enunciados sem texto? Tradução de Ana Raquel Motta. In: POSSENTI, S.; SOUZA-E-SILVA, M. C. P. de (Org.) Doze conceitos em análise do discurso. São Paulo: Parábola, 2010. p. 9-24.

MAINGUENEAU, D. Enunciação ligada, enunciação desatada. Tradução de Leci Borges Barbisan, com revisão do autor. In: DI FANTI, M. da G.; BARBISAN, L. B. (Org.) Enunciação e discurso. São Paulo: Contexto, 2012a. p. 13-24.

MAINGUENEAU, D. Texto, gênero do discurso e aforização. Tradução de Ana Raquel Motta. In: BRAIT, B.; SOUZA-E-SILVA, M. C. P. (Org.). Texto ou discurso? São Paulo: Contexto, 2012b. p. 109128.

MAINGUENEAU, D. Análise de textos de comunicação. Tradução de Maria Cecília Perez de Souza-eSilva e de Décio Rocha. 6. ed. ampl. São Paulo: Cortez, 2013.

MAINGUENEAU, D. Frases sem texto. Tradução de Sírio Possenti et alii. São Paulo: Parábola, 2014.

POSSENTI, S. Novos objetos e novos conceitos: a Análise do Discurso se move. In: SARGENTINI, V; GREGOLIN, M. do R. (Org.) Análise do discurso: heranças, métodos e objetos. São Paulo: Claraluz, 2008. p. 59-68.

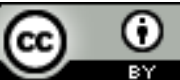

Este texto está licenciado com uma Licença Creative Commons Atribuição 4.0 Internacional. 